goals. Experts from around the world called on the UK's Department for International Development and the international community to give much greater emphasis to population and family planning. Baige Zhao, vice minister of the National Population and Family Planning Commission of China offered "to share our information and also our commodities."10 As China reaches out to help other countries, their contribution to international family planning could prove an important additional global benefit of the sacrifices the Chinese people made to implement the one child policy.

\section{Malcolm Potts Fred H Bixby endowed chair}

(potts@berkeley.edu)

School of Public Health, University of California, Berkeley, CA 94720-7360, USA

Competing interests: None declared.

1 Potts M. Sex and the birth rate: human biology, demographic change and access to fertility regulation methods. Popul Dev Rev 1997;23:1-40.
2 Chen P-C. Rural health and birth planning in China. North Carolina: International Fertility Regulation Program, 1981.

3 Birdsall N, Kelly A, Sinding SW. Population matters: demographic change, economic growth and poverty in the developing world. Oxford: Oxford University Press, 2001.

4 Feng W, Mason A. Demographic dividend and prospects for economic development in China. United Nations Expert Group on Social and Economic Implications of Changing Population Age Structure, UN/POP/PD/ 2005/5, 2005.

5 Ding QJ, Hesketh T. Family size, fertility preferences, and sex ratio in China in the era of the one child family policy: results from national family planning and reproductive health survey. BMJ 2006;333:371-3.

6 Greenhalgh S. Science, modernity, and the making of the one-child policy. Popul Dev Rev 2003;29:163-96.

7 Zimmer Z, Kwong J. Family size and support of older adults in urban and rural China: current effects and future implications. Demography 2003;40:23-44.

8 Hesketh T, Xing ZW. The effect of China's one-child family policy after 25 years. N Engl J Med 2005;353:1171-6.

9 World Bank. Niger: providing all Nigeriens with food, education and health care; a demographic perspective. World Bank report 34219-NE, 2005.

10 All Party Parliamentary Group on Population, Development and Reproductive Health. 2006 hearings: oral evidence, hearing 4. www.appgpopdevrh.org.uk/Publications/Population $\% 20$ Hearings/

Population\%20Hearings.htm (last accessed 3 Aug 2006).

doi 10.1136/bmj.38938.412593.80

\title{
Overweight and obesity in China
}

\section{The once lean giant has a weight problem that is increasing rapidly}

$\mathrm{A}$ bout one fifth of the one billion overweight or obese people in the world are Chinese. China was once considered to have one of the leanest populations, ${ }^{1}$ but it is fast catching up with the West in terms of the prevalence of overweight and obesity; disturbingly, this transition has occurred in a remarkably short time. ${ }^{2}$

Data from the 2002 national nutrition and health survey showed that $14.7 \%$ of Chinese were overweight (body mass index $\left(\mathrm{BMI} ; \mathrm{kg} / \mathrm{m}^{2}\right) \geq 25$ ) and another $2.6 \%$ were obese $(\mathrm{BMI} \geq 30)$, such that there are currently (2002) 184 million overweight people, and a further 31 million obese people, in China, out of a total population of 1.3 billion (table). ${ }^{3}$ Although the prevalence of obesity in China is relatively low compared with Western countries such as the United States, where over half of adults are either overweight or obese, it is the rapid increase of the condition, ${ }^{4}$ especially among children, that is particularly alarming. Data from the China national surveys on the constitution and health in school children showed that the prevalence of overweight and obesity in children aged 7-18 years increased 28 times and obesity increased four times between 1985 and 2000 (figure), ${ }^{5}$ a trend that was particularly marked in boys.

Increasing evidence indicates that the World Health Organization's definitions of overweight (BMI $>25)$ and obesity (BMI >30) may underestimate the true burden of the condition. These cut points are derived from white populations and hence may not be applicable to Asians. On the basis of a meta-analysis of associations of BMI with risk factors for cardiovascular disease among 240000 Chinese adults, and of the longitudinal relationships of BMI to cardiovascular events in 76000 participants, the Working Group on Obesity in China has recommended that a BMI of 18.5 to 23.9 should be considered as optimal, 24.0 to 27.9 as overweight, and 28.0 and above as obese. ${ }^{67}$ These rec- ommendations have been used in the guidelines for prevention and control of overweight and obesity in Chinese adults. ${ }^{8}$ Using these cut points rather than the WHO definitions would increase the prevalence of overweight and obesity in China by a further 66 million, to over a quarter of a billion people (table). More informative measures of obesity, such as waist circumference or waist:hip ratio, are considered to be more strongly correlated with cardiovascular risk and may be more appropriate for use in Asian populations, in whom central adiposity has been shown to occur at lower levels of BMI than in white people.

The explanations of China's recent epidemic of overweight and obesity include changes to the traditional diet, reduced levels of physical activity, and increased sedentary lifestyles. Recent data from the national surveys of nutrition indicate noticeable

BMJ 2006;333:362-3

Prevalence of overweight and obesity in national nutrition and health survey 2002 and estimated number of overweight and obese people in China

\begin{tabular}{|c|c|c|c|c|c|c|c|}
\hline \multirow[b]{2}{*}{$\begin{array}{l}\text { Age } \\
\text { group }\end{array}$} & \multirow[b]{2}{*}{$\begin{array}{c}\text { No } \\
\text { surveyed }\end{array}$} & \multicolumn{3}{|c|}{ Prevalence $(\%)^{*}$} & \multicolumn{3}{|c|}{ Estimated No (million)† } \\
\hline & & Overweight & Obesity & $\begin{array}{l}\text { Overweight } \\
\text { and obesity }\end{array}$ & Overweight & Obesity & $\begin{array}{l}\text { Overweight } \\
\text { and obesity }\end{array}$ \\
\hline \multicolumn{8}{|c|}{ China criteriał } \\
\hline$\overline{0-6}$ & 24947 & 3.4 & 2.0 & 5.4 & 4 & 2 & 6 \\
\hline $7-17$ & 44880 & 4.5 & 2.1 & 6.6 & 10 & 5 & 15 \\
\hline$\geq 18$ & 140022 & 22.8 & 7.1 & 29.9 & 200 & 60 & 260 \\
\hline$\overline{\text { Total }}$ & 209849 & 17.6 & 5.6 & 23.2 & 214 & 67 & 281 \\
\hline \multicolumn{8}{|c|}{ WHO criteria§ } \\
\hline$\overline{0-7}$ & 24947 & 3.4 & 2.0 & 5.4 & 4 & 2 & 6 \\
\hline $7-17$ & 44880 & 4.2 & 1.8 & 6.0 & 10 & 4 & 14 \\
\hline$\geq 18$ & 140022 & 18.9 & 2.9 & 21.8 & 170 & 25 & 195 \\
\hline Total & 209849 & 14.7 & 2.6 & 17.3 & 184 & 31 & 215 \\
\hline
\end{tabular}

${ }^{*}$ Standardised by age and social economic status according to 2000 national census. †Population in 2000 census $\times$ prevalence.

ҒAge 0-6, as WHO criteria; age 7-17: overweight BMI $\geq 85$ th centile, Working Group on Obesity in China, obesity BMI 295 th centile; age 18 and over: overweight BMI 24-<28, obesity BMI $\geq 28$.

$\S$ Age $<7$ years: overweight $2<$ WHO Z score $\leq 3$, obesity WHO Z score $>3$; age $7-17$ : overweight $B M I \geq 85$ th

WHO centile, obesity BMI $\geq 95$ th centile; age 18 and over: overweight BMI $25-<30$, obesity BMI $\geq 30$. 


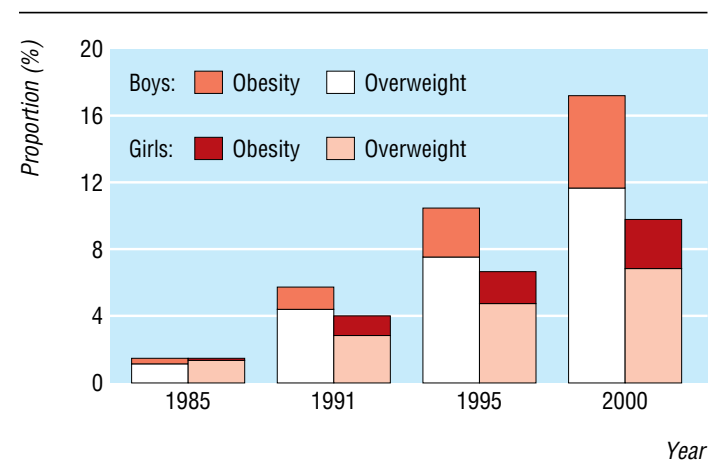

Overweight and obesity in schoolchildren aged 7-18 in large cities in China ${ }^{5}$

changes in the proportions, and sources, of dietary macronutrients over the past 20 years. Energy intake from animal sources has increased from 8\% in 1982 to $25 \%$ in $2002,{ }^{3}$ and the average energy intake from dietary fat among urban Chinese increased from 25\% to $35 \%,{ }^{9}$ which is above the upper limit of $30 \%$ recommended by the WHO. The obesity epidemic in China may also have its roots in the prevailing social attitudes towards body fatness. In Chinese culture, there is still a widespread belief that excess body fat represents health and prosperity. This is perhaps a consequence of China's recent history, where famine and chronic malnutrition caused the deaths of millions of people in the $1950 \mathrm{~s}$.

Coinciding with China's continuing modernisation are reductions in physical activity and labour intensity in both urban and rural areas. People are expending less energy on traditional forms of transportation such as walking and cycling, and the popularity of cars, buses, and motorcycles is increasing. Data from the national statistics bureau show that the number of cars produced in China quadrupled from 5400 in 1980 to over 2 million in 2003-almost all of which are sold in China. Furthermore, the lack of consideration towards constructing environments in inner cities that promote physical activity has meant that it has become increasingly difficult to find safe places in residential areas to exercise or even walk.

As in other countries, China's epidemic of overweight and obesity poses a considerable public health problem, and it is becoming increasingly clear that we need to act now to prevent any further increase. The means by which this may be accomplished remain elusive. In randomised trials, intensive lifestyle education has been shown to result in modest but sustained weight loss; the feasibility and efficacy of conducting such studies in China is uncertain but should be investigated. As a first step, the prevention and control of obesity should be listed in China's framework and policy on health. By confronting the challenge now, China may be able to halt the growing problem of overweight and obesity, doing what the West has so far failed to do.

Yangfeng Wu professor and chief

(yangfengwu@263.net)

Department of Epidemiology, Cardiovascular Institute and Fu Wai Hospital, Chinese Academy of Medical Sciences, \#167, Beilishilu, Xicheng, Beijing 100037, People's Republic of China

Competing interests: YW is currently the director of the WHO Collaborating Center for Cardiovascular Disease Prevention, Control, and Research in China; a council member of the Asian-Pacific Society of Atherosclerosis and Vascular Diseases, the Chinese Society of Tobacco or Health, the Chinese Hypertension League, and the Chinese Medical Doctors Association Hypertension Branch and Health Promotion and Health Management Branch; a member of the Working Group on Obesity in China; and vice-chair of the Beijing Hypertension Prevention and Control Society. He does not receive money for these positions.

1 WHO-MONICA Project. Risk factors. Int J Epidemiol 1989;18(suppl 1):S46-55.

2 Ma G, Li Y, Wu Y, Zhai F, Cui Z, Hu X, et al. The prevalence of body overweight and obesity and its changes among Chinese people during 1992 to 2002. Chin J Prev Med 2005;39:311-5. (In Chinese, with English abstract.)

3 Wu Y, Ma G, Hu Y, Li Y, Li X, Cui Z, et al. The current prevalence status of body overweight and obesity in China: data from the China nutrition and health survey. Chin J Prev Med 2005;39:316-20. (In Chinese, with English abstract.)

abstract.

World Health Organization. Preventing chronic disease: a vital investment: WHO global report. Geneva: WHO,2005:56. www.who.int/chp chronic_disease_report/contents/en/index.html (accessed $27 \mathrm{Apr}$ 2006).

5 Ji C, Sun J, Chen T. Dynamic analysis on the prevalence of obesity and overweight school-age children and adolescents in recent 15 years in China. Chin J Epidemiol 2004;25:103-8. (In Chinese, with English abstract.)

6 Cooperartive Meta-analysis Group of the Working Group on Obesity in China. Predictive value of body mass index and waist circumference for risk factors of certain related diseases in Chinese adults-study on optimal cut-off points of body mass index and waist circumference in optimal cut-off points of body mass index and

7 Chinese adults. Biomed Environ Sci 2002;15:83-95. China. Effect of body mass index on all-cause mortality and incidence of cardiovascular diseases-report for meta-analysis of prospective studies on optimal cut-off points of body mass index in Chinese adults. Biomed Environ Sci 2002;15:245-52.

8 Working Group on Obesity in China, Department of Disease Control, Ministry of Health. The guidelines for prevention and control of overweight and obesity in Chinese adults. Biomed Environ $S$ 2004:17:1-35.

9 Wang L, ed. The status in nutrition and health in China. Beijing: People's Medical Publishing House, 2005.

\section{Meeting the needs of elderly people in China}

\section{Community health care is a good idea but unsatisfactorily implemented}

$\mathrm{L}$ ike its neighbours Thailand and South Korea, ${ }^{1-3}$ China is facing the challenge of a rapidly aged over 65 reached $6.9 \%$ in 2000 and is predicted to be as high as $22.7 \%$ in 2050. ${ }^{4}$ Although the Chinese population is currently younger than the UK population (which in 2002 had 16\% of people over
$65),{ }^{5}$ the proportion of older people is growing faster than in the UK. People over 60 currently make up $10.9 \%$ of the population in China, projected to rise to $31.0 \%$ in 2050 , compared with $21.2 \%$ rising to $29.4 \%$ in the United Kingdom.

Ageing leads to increased healthcare needs and to changes in the modes and content of healthcare delivery-from narrow, merely medical treatment to integrated, community based health care, for example. 